\title{
Proposta para a recuperação ambiental das nascentes e da área verde do lotea- mento Cidade Universitária, município de Passo Fundo/RS
}

\author{
Alcindo Neckel ${ }^{1}$ \\ ${ }^{1}$ Universidade Federal do Rio Grande do Sul. Programa de Pós-Graduação em Geografia. E-mail: alcindoneckel@yahoo.com.br \\ Recebido em 07/2012. Aceito para publicação em 10/2013. \\ Versão online publicada em 08/11/2013 (http://seer.ufrgs.br/paraonde)
}

\begin{abstract}
Resumo - As áreas verdes de uma cidade normalmente são regidas pelos planos de desenvolvimento propostos pelos municípios. Entretanto, propostas de melhorias geralmente são levadas pela comunidade aos órgãos competentes, como: Prefeitura Municipal e Ministério Público. Este trabalho foi desenvolvido como subsídio para possíveis melhorias na área verde do Loteamento Cidade Universitária, no município de Passo Fundo/RS, visando assim, adequa-lá ao seu propósito original. As etapas do desenvolvimento metodológico do trabalho são: levantamento bibliográfico; mapeamento da área e da vegetação existente; diagnóstico socioeconômico das famílias residentes no loteamento, realizado através de questionário dirigido, em que foi investigada a percepção de meio ambiente por parte dos moradores; Propostas para: o reflorestamento da área com espécies arbóreas nativas, a limpeza e proteção das nascentes. Os resultados obtidos no diagnóstico socioeconômico demonstraram uma possível conscientização da comunidade para a recuperação da área de estudo. Com essas ações, a área verde passou a ter uma função social para a comunidade, a qual, doravante, atua ativamente na preservação do local, através das propostas de melhorias sugeridas neste artigo.stein.
\end{abstract}

Palavras-chave: Área degradada. Proteção de nascentes. Recursos hídricos.

\section{INTRODUÇÃO}

A urbanização no Brasil teve um "relativo salto evolutivo principalmente no século XIX e XX, onde está relacionada diretamente à expressão industrialização, destacando-se o crescimento urbano". Neste período surgiram novas cidades repletas de espaços construídos e espaços não construídos (SANTIAGO; MEDEIROS, 2002, p. 48), fruto do modelo urbanístico de desenvolvimento implantado no País.

Segundo, Carvalho (2003), no urbanismo, através de influência européia, se buscou algumas medidas, no sentido de abrandar o problema, implantando assim, espaços de passeios e jardins públicos. Estas ações mitigadoras objetivaram colocar as áreas verdes como agentes responsáveis pelo resgate do bem estar da população (FEIBER, 2004).

Este cenário não é diferente para a comunidade do Loteamento Cidade Universitária, localizada na cidade de Passo Fundo/RS, que possui uma área verde com problemas de preservação. A área foi historicamente manejada de forma inadequada, tanto na sua função urbana, quanto ambiental.
Através da mobilização da comunidade, propostas foram apresentadas a órgãos como Prefeitura Municipal e Ministério Público, a fim de torná-la em um parque urbano, que ao mesmo tempo preservaria o ambiente e serviria de área de lazer à comunidade.

A pesquisa foi desenvolvida, com o objetivo de analisar e caracterizar a área verde e dar auxílio técnico e científico à comunidade, no planejamento e na execução das propostas de melhorias, observando as leis de preservação ambiental e as necessidades locais dos moradores do Loteamento Cidade Universitária.

\section{A URBANIZAÇÃO E AS QUESTÕES AMBIENTAIS}

A formação das cidades brasileiras, desde 1950, vem construindo um cenário de contrastes, típico das grandes cidades do Terceiro Mundo. A maneira como foi criada a maioria dos municípios acabou se sobrepondo aos modelos tradicionalmente utilizados de organização do território e da gestão urbana, que se mostrou inadequada, pois conforme Nefussi e Licco (2005), como resultados disso surgem cidades sem infraestrutura adequada, incapazes de comportar o crescimento

${ }^{1}$ Pesquisa desenvolvida para Dissertação de Mestrado do Programa de Pós Graduação em Engenharia da Universidade de Passo Fundo/ RS - Brasil. 
populacional, em condições dignas de moradia, transporte, saúde, educação, etc...

Como os espaços urbanos diferem entre si, há variação nos impactos ambientais gerados. Isto pode ser identificado no Quadro 1.

Quadro 1. Comparação dos aspectos do gerenciamento da água no meio urbano.

Fonte: Tucci apud Fiori et al (2008, p.3).

\begin{tabular}{|c|c|c|}
\hline $\begin{array}{l}\text { Infraestrutura } \\
\text { urbana }\end{array}$ & Países desenvolvidos & Brasil \\
\hline Abastecimento de água & $\begin{array}{l}\text { Resolvido, com cobertura } \\
\text { total. }\end{array}$ & $\begin{array}{l}\text { Grande parte } \\
\text { atendida, } \\
\text { tendência de } \\
\text { redução da } \\
\text { disponibilidade } \\
\text { devido à } \\
\text { contaminação, } \\
\text { grande quantidade } \\
\text { de perdas na rede. }\end{array}$ \\
\hline Saneamento & Cobertura quase total. & $\begin{array}{l}\text { Falta de rede } \\
\text { e de estações } \\
\text { de tratamento; } \\
\text { as que existem } \\
\text { não conseguem } \\
\text { coletar e tratar } \\
\text { o esgoto como } \\
\text { projetado. }\end{array}$ \\
\hline Drenagem urbana & $\begin{array}{l}\text { Controlados os } \\
\text { aspectos quantitativos; } \\
\text { desenvolvimento de } \\
\text { investimentos para controle } \\
\text { dos aspectos de qualidade } \\
\text { da água. }\end{array}$ & $\begin{array}{l}\text { Grandes } \\
\text { inundações } \\
\text { devido a falta de } \\
\text { ampliação das } \\
\text { redes. Aspectos } \\
\text { de qualidade } \\
\text { da água nem } \\
\text { mesmo foram } \\
\text { identificados. }\end{array}$ \\
\hline Inundações ribeirinhas & $\begin{array}{l}\text { Medidas de controle não } \\
\text { estruturais como seguro e } \\
\text { zoneamento de inundação. }\end{array}$ & $\begin{array}{l}\text { Grandes prejuízos } \\
\text { por falta de } \\
\text { política de } \\
\text { controle. }\end{array}$ \\
\hline
\end{tabular}

A degradação ambiental está fortemente ligada a fatores de uso e ocupação do solo, uma vez que estas ocasionam o tipo e o grau de impacto, o qual atinge de maneira diferente o ambiente. Assim, o uso do solo diversifica-se a partir de sua ocupação por diferentes categorias sociais, daí a necessidade de se considerar fatores políticos, econômicos, culturais e bióticos para a análise dos processos de degradação ambiental (FANTON, 2007).

Nesse contexto, as cidades poderão passar de zonas de grandes distúrbios sociais, políticos, econômicos e ecológicos, para locais de crescimento cultural e de compartilhamento de idéias, tanto ecológicas quanto tecnológicas. Essa parece ser a única forma de sobrevivência futura, pois a gestão é a superação de problemas, especialmente fatores de injustiça social e de melhoria da qualidade de vida. Ambos deveriam ser vistos como pertencendo ao amplo domínio das estratégias de desenvolvimento local, regional e nacional. Isso permite que o planejamento e a gestão urbana, vistos pela ótica de ciência social, nada mais sejam do que estratégias de desenvolvimento urbano, alimentadas por pesquisa social básica, tanto teórica quanto empírica (SOUZA, 2004).

0 crescimento das cidades e dos aglomerados urbanos geralmente reforça os problemas de ordem ambiental. As agressões ao meio ambiente decorrem de um somatório de fatores ligados, basicamente, ao uso e à ocupação desordenados do solo, ao crescimento da malha urbana sem o acompanhamento adequado de recursos de infraestrutura e à expansão imobiliária. Assim, áreas inadequadas são ocupadas pela população carente, ou mesmo por empreendimentos imobiliários de média e alta renda. Isso contribui para a falta de tratamento paisagístico adequado às atividades e necessidades dos usuários (LORENSINI et al., 2008).

Se os processos naturais fossem reconhecidos e aproveitados, representariam um poderoso recurso para a construção de um habitat urbano sustentável. Mas quando ignorados, ampliam os problemas que cada vez mais castigam as cidades, como deslizamentos, enchentes, poluição do ar e da água (CHAFFUN, 1997).

Para aproveitar as oportunidades inerentes ao ambiente natural da cidade, torna-se necessária uma nova atitude para com o ambiente construído, pois a cidade precisa ser reconhecida como parte da natureza e por isso necessitasse de preservação (SOUZA, 2004). A cidade pode ser entendida como um ecossistema, em seu sentido amplo, uma unidade ambiental, dentro da qual todos os elementos e processos do ambiente são interrelacionados e interdependentes, de modo que uma mudança em um deles resultará em alterações em outros componentes. Porém, há também diferenças ideológicas e os conflitos de interesses que se confrontam no ideário ambiental refletindo dentro do cenário urbano (LEFF, 2003).

Os grandes assentamentos urbanos concentram, também, os maiores problemas ambientais, tais como poluição do ar, sonora e hídrica; destruição dos recursos naturais; desintegração social; desemprego; perda de identidade cultural e de produtividade econômica. Muitas vezes, as formas de ocupação do solo, o provimento de áreas verdes e de lazer, o gerenciamento de áreas de risco, o tratamento do esgoto e a destinação final do lixo coletado deixam de ser tratados com a prioridade que merecem. A Constituição Brasileira de 1988 tornou obrigatório o Plano Diretor para os municípios com mais de vinte mil habitantes, definindo-o como o instrumento básico da política de desenvolvimento e expansão urbana, meio de expressão das "exigências 
fundamentais de ordenação da cidade", e como parâmetro para assegurar a função social da propriedade urbana (CHAFFUN, 1997).

Nesse sentido, uma das evidências preocupantes dentro da cidade é a questão dos problemas sobre a degradação dos recursos hídricos, localizados geralmente nas zonas envolventes das áreas edificadas, nos trechos urbanos, que recebem descargas de águas residuais domésticas e industriais, adicionando-se ainda a destruição da mata ciliar e a canalização, trazendo consequências diretas ao nível do ecossistema ribeirinho (TEIGA et al., 2007). Atualmente, no cenário urbanístico, a água torna-se uma preocupação, pois mesmo sendo um recurso natural renovável, em se tratando de água potável, o consumo é cada vez maior, e o saneamento básico nem sempre chega a todas as residências. Sabe-se que o esgoto é direcionado para arroios e/ou córregos, tornando-os altamente poluídos. Magossi e Bonacella (2003, p. 34) comentam que "a contaminação das águas pelo esgoto urbano resulta em dois problemas muito sérios: a contaminação por bactérias causadoras de doenças e a contaminação por substâncias orgânicas capazes de serem transformadas por microorganismos".

O quadro de desequilíbrio dos recursos hídricos urbanos, com os problemas ambientais associados às enchentes e à deterioração da qualidade das águas, resulta não só na descarga de efluentes, mas também na ocupação inadequada do solo das bacias urbanas (BRAGA; CARVALHO, 2003).

As matas ciliares são ecossistemas estruturalmente complexos tendo, segundo Marques Neto e Viadana (2006, p.11), "a responsabilidade de associar um grande número de espécies que buscam as condições favoráveis desses ambientes para a reprodução, pela disponibilidade de alimento, água, entre outros fatores". Isto vem ao encontro desta pesquisa, onde se entende que a recuperação das nascentes de uma área verde é fundamental para a conservação do ecossistema local.

\section{ÁREAS VERDES}

Segundo Lima et al. (1994), na tentativa de definir área verde, através de consultas a profissionais que trabalham nessa área chega ao seguinte conceito: Área Verde: Espaço onde há o predomínio de vegetação arbórea, englobando as praças, os jardins públicos e os parques urbanos. Os canteiros centrais de avenidas e os trevos e rotatórias de vias públicas, que exercem apenas funções estéticas e ecológicas, devem, também, conceituar-se como área verde. Entretanto, as árvores que acompanham o leito das vias públicas, não devem ser consideradas como tal, pois as calçadas são impermeabilizadas.

Neste sentido, podem-se considerar as áreas verdes como aquelas onde não há pavimentação ou construção de calçadas, pois isto impede a permeabilidade do solo (MIANA, 2010). Já, Toledo e Santos (2007), usam o termo áreas verdes para designar diversos tipos de espaços urbanos que podem ser públicos ou particulares e são abertos, acessíveis e relacionados com saúde e recreação.

Entretanto, de acordo com Lima et al. (1994) espaço livre torna-se um termo mais abrangente que áreas verdes, sendo o sistema de áreas verdes entendido como integrante do sistema de espaços livres. Esta concepção é sustentada, também, por Nucci (2001), que denomina estas áreas como um subsistema do sistema de espaços livres e que devem fornecer possibilidade de lazer à população.

Para Lima et al. (1994), dentre os espaços livres tem-se os parques urbanos, as praças, a arborização e as áreas verdes. Estas são, segundo os autores, áreas onde há o predomínio de vegetação arbórea, devendo ser consideradas as praças, os jardins públicos e os parques urbanos, além dos canteiros centrais e trevos de vias públicas, que têm apenas funções estéticas e ecológicas.

Já, Mazzei et al. (2007, p. 35), considera as áreas verdes como uma categoria dos espaços livres de construção. Além disso, para eles os termos áreas verdes e espaços livres não são sinônimos e o planejamento das áreas verdes visa "atender a demanda da comunidade urbana por espaços abertos que possibilitem a recreação, o lazer e a conservação da natureza". Conforme suas avaliações,

[...] as áreas verdes não são necessariamente voltadas para recreação e lazer objetivos básicos dos espaços livres, porém devem ser dotadas de infra-estrutura e equipamentos para oferecer opções de lazer e recreação às diferentes faixas etárias, a pequenas distâncias da moradia (que possam ser percorridas a pé) (MAZZEI et al., 2007, p. 39).

Um fator considerável, segundo Hardt (1994), apud Hulsmeyer \& Souza (2007), a permeabilidade do solo em áreas urbanas está, normalmente, relacionada aos espaços naturais, demonstrando, na maioria das vezes, melhoria na qualidade ambiental. Neste contexto, Oliveira (1996), considera a importância da permeabilidade do solo nas áreas verdes, sendo que, para ele, um conceito de áreas verdes completo necessita descrever suas estruturas e enfatizar, sobretudo, a importância que elas têm em termos de suas funções (ecológicas, estéticas, econômicas e sociais).

\section{METODOLOGIA}

O objeto de estudo é uma área verde com cerca de $2.000 \mathrm{~m}^{2}$ e está situada no Loteamento Cidade Universitária - LCU, Bairro Petrópolis no município de Passo Fundo, situado ao norte do Estado do Rio Grande do Sul, conforme a Figura 1.

Para atingir os objetivos do trabalho, de caracterização da área e dos problemas existentes, de orien- 


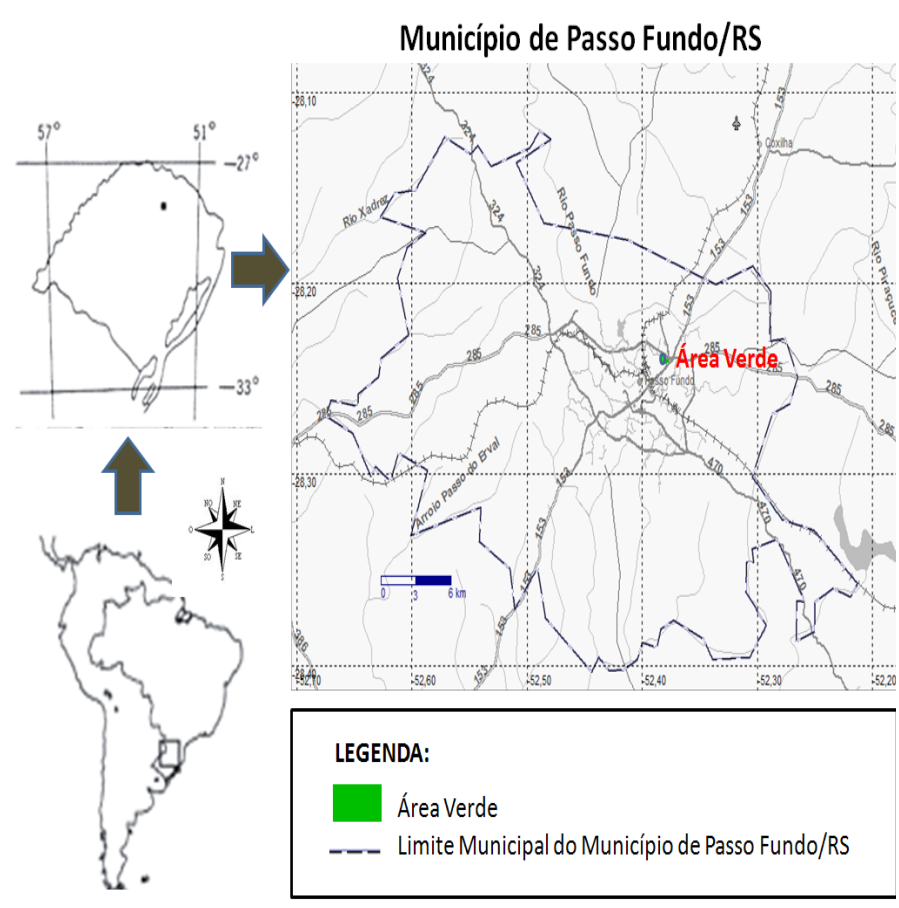

Figura 1. Localização do Município de Passo Fundo/RS. Fonte: Adaptado de Zanella e Cechin (2006, p. 212).

tação à comunidade no planejamento e execução de melhorias, dentro do que regem as leis de preservação ambiental. Diante das suas necessidades e de aplicação de um projeto de recuperação, visando à preservação das nascentes, foram realizadas ações, tais como:

a) Levantamento bibliográfico sobre o tema abordado;

b) Aplicação de questionário à comunidade: aplicou-se a toda população no entorno da área de estudo, onde foram coletados os dados de trinta e três domicílios. Elaborou-se questões socioeconômicas e ambientais sobre o tempo de residência no loteamento, a eventual visita de agentes de saúde às residências, a coleta de lixo, entre outras; tente;

c) Mapeamento da área quanto à vegetação exis-

d) Análise de água das três nascentes para conhecer qualidade da água; e a análise do solo em diferentes pontos na área estudada;

f) Aplicação de um projeto para a recuperação dos recursos hídricos. Esse projeto prevê a recuperação das nascentes e do solo através do plantio de quinhentas mudas nativas e a criação de uma praça para o lazer da comunidade.

\section{RESULTADOS E DISCUSSÃO}

Ao final da primeira etapa da pesquisa, com as informações coletadas foi possível elaborar um diagnóstico do objeto de estudo.

A área verde tem aproximadamente dois hectares e está situada no Loteamento Cidade Universitária, Bairro Petrópolis na cidade de Passo Fundo/RS. É atualmente ocupada pela Delegacia Civil e por uma sociedade tradicionalista. Nela concentram-se três nascentes com problemas de preservação: uma delas foi canalizada e as outras duas estão degradadas pela inexistência da mata ciliar, restando apenas pequenos remanescentes de mata secundária. 0 Arroio Invernadinha, localizado a Sudoeste da área verde, sofre com a degradação, pois recebe a água das três nascentes, com consequente aumento de sua vazão.

Esses problemas decorrem da urbanização, da presença de construções e da degradação, caracterizada pela eliminação da vegetação e da camada de solo fértil, modificando totalmente o espaço. Estas informações, segundo Oliveira e Bitar (2009, p. 13), necessitam ser coletadas, objetivando-se "a consulta por parte de outros gestores que enfrentam problemas semelhantes", para que possam agir sobre as problemáticas identificadas.

As análises de água (microbiológica), das três nascentes, e do solo, em diferentes pontos na área estudada, apresentaram contaminação por coliformes fecais. Conforme Rotta, Neckel e Goellner (2012, p. 11), "a Lei 9.605 de 12 de fevereiro de 1998 Art. 54 adverte. Aquele que causar poluição de qualquer natureza em níveis tais que resultem ou possam resultar em danos à saúde humana, ou que provoquem a mortandade de animais ou a destruição significativa da flora", devem ser responsabilizados, por tais crimes.

$\mathrm{Na}$ segunda etapa da pesquisa, as respostas às questões socioeconômicas revelaram o cenário relatado a seguir: $43 \%$ dos entrevistados afirmaram morar no loteamento há até cinco anos, $21 \%$ residem entre seis e dez anos, $15 \%$ entre onze e quinze anos, $15 \%$ entre dezesseis e vinte anos e $6 \%$ não informaram, Conforme pode ser observado pela Figura 2.

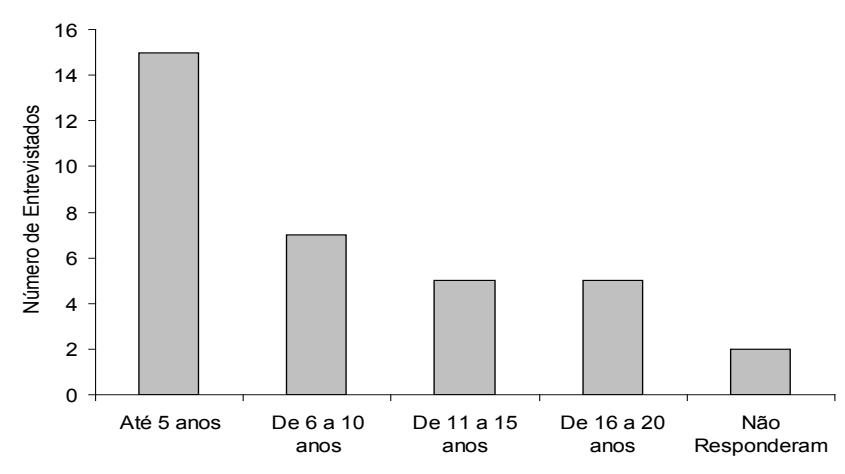

Figura 2. Tempo de moradia no local.

Observa-se que a grande maioria dos moradores está há menos de cinco anos no loteamento, o que comprova que o local é de habitação recente. Porém, a degradação existente na área verde, não se limita somente há este tempo, pois sua ocorrência data de tempos, ainda, anteriores da Lei de criação do Loteamento Cidade Universitária.

$\mathrm{Na}$ área em estudo localiza-se o Arroio Invernadinha, o qual recebe a água de três nascentes, conforme a Figura 3. 


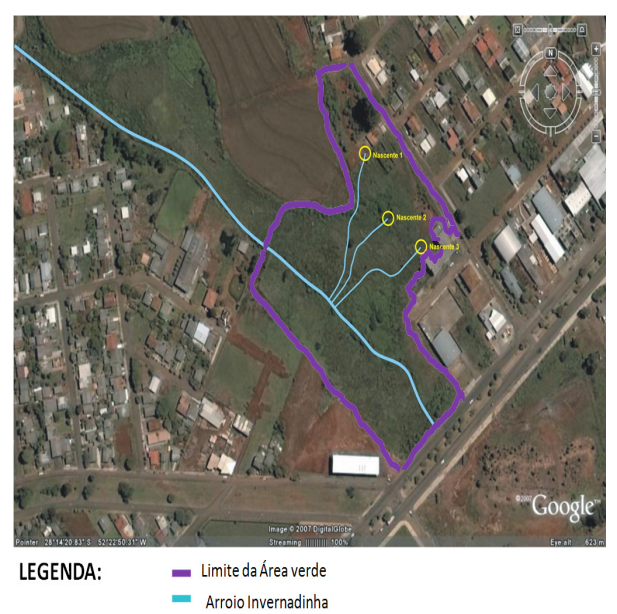

Figura 3. Localização das nascentes do Arroio Invernadinha. Fonte: Adaptado do Googleearth (2011).

No que se refere à visita de agentes de saúde, 21\% dos moradores afirmaram receber visitas periódicas, $76 \%$ responderam não receber visita de agentes de saúde e 3\% não responderam. É previsto em lei que as visitas de agentes de saúde devem ocorrer periodicamente em todas as residências para o acompanhamento devido. Entretanto, percebe-se que essa comunidade do Loteamento Cidade Universitária encontra-se em situação de possível abandono por parte do Poder Público, responsável por garantir qualidade de vida à população.

Quando questionados sobre a coleta de resíduos domiciliares na rua de sua residência, $100 \%$ dos entrevistados responderam afirmativamente que o mesmo é coletado pela Prefeitura Municipal. Porém, há o problema dos resíduos que se encontram em locais inadequados, às margens da rua e em terrenos baldios. Este problema deve ser combatido com a sensibilização da comunidade com maiores informações a respeito da poluição ambiental causada por tal hábito, através de um trabalho de conscientização de longo prazo.

\section{PROPOSTAS PARA O PROJETO DE RECUPERAÇÃO}

As sugestões para a recuperação dos recursos hídricos da área verde foram feitas para a comunidade do entrono que se encontrava mobilizada . Nisto, foram agrupadas em três grupos de estratégias:

1) proteção das nascentes;

2) recuperação da vegetação da área em geral, identificada como as zonas $1 \mathrm{a}$ e $2 \mathrm{~b}$;

3) manejo da área de lazer, identificado como a zona 2a, ao norte da área.

Para a zona definida como 1a, onde se encontram as nascentes, foram realizadas as seguintes ações:

- Limpeza da área, para restaurar a condição natural do meio.

- Eliminação da vegetação exótica, como pínus e eucalipto, espécies que interfeririam no crescimento e desenvolvimento das mudas nativas implantadas. Caso haja necessidade, essa ação também poderá ser adotada no total da área.

- Revegetalização do solo, num raio de $50 \mathrm{~m}$ das nascentes, com base na Lei no 7.803 de 18.7.1989 e no Artigo 2ำ do Código Florestal Estadual.

- Monitoramento da qualidade da água do ponto de vista organoléptico, químico e microbiológico.

- A escolha das espécies de vegetação foi realizada de acordo com a velocidade de crescimento e o potencial de contribuição para a recuperação ambiental. Também se observou à disponibilidade de mudas e sementes provenientes de doações.

As espécies nativas herbáceas e de forração foram plantadas, em um primeiro momento, a fim de cobrir o solo, assim como, as plantas arbóreas. Em uma etapa subsequente a preparação do solo e a introdução de espécies nativas foram realizadas, com base em um modelo que intercala espécies pioneiras, secundárias e climáticas em um espaçamento linear de $4 \times 4$ metros.

A Figura 4 representa a estratégia de plantio das mudas nas Zonas $1 \mathrm{a}$ e $2 \mathrm{~b}$.

\begin{tabular}{|c|c|}
\hline 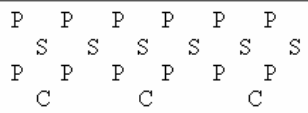 & \\
\hline 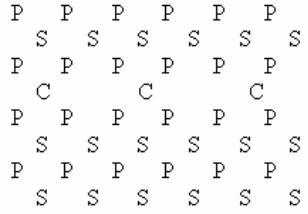 & $\begin{array}{l}\text { Legenda } \\
\mathrm{P}=\text { Pioneiras }-2 \times 2 \mathrm{~m} \\
\mathrm{~S}=\text { Secundárias }-2 \times 4 \mathrm{~m} \\
\mathrm{C}=\text { Climáticas }-6 \times 4 \mathrm{~m}\end{array}$ \\
\hline
\end{tabular}

Figura 4. Representação adotada na área verde para a distribuição das espécies pioneiras, secundárias e climáticas.

Esse método se aplica com bons resultados para pequenas áreas. É um modelo bastante denso, que comporta quatro mil plantas por hectare. Entre as mudas plantadas, sobre as entrelinhas, foram semeadas gramíneas estoloníferas como a Paspalun notatun. Esta prática auxilia na preservação e limpeza das entrelinhas sem a germinação de espécies infestantes exóticas.

Quanto às ações para a melhoria e preservação da área verde do Loteamento Cidade Universitária podem ser citadas:

- Proteção das nascentes d'água;

- Florestamento das áreas adjacentes às nascentes com espécies florestais nativas como corticeiras, açoitas cavalos, pitangas, angicos, ipês, guabiroba, bracatinga (pioneira), araucária e cedro;

- Preservação da área de lazer para crianças e adultos;

- Criação de trilhas para caminhadas.

\section{CONSIDERAÇÕES FINAIS}

A pesquisa atingiu seu propósito de diagnosticar 
e analisar a situação da área verde do Loteamento Cidade Universitária na cidade de Passo Fundo, assim como, propor sugestões de melhorias com relação das questões ambientais e de urbanização.

Todos os entrevistados se comprometeram em auxiliar no que fosse necessário para a preservação da área verde do espaço público e do terreno onde se localiza a sua residência, para que o lugar onde residem se torne mais agradável e ambientalmente mais adequado.

As ações da comunidade foram acompanhadas durante o período de 2005 a 2007, após o qual foi possível perceber que sua organização no processo de reivindicação para execução das propostas de melhoria. A vegetação da área foi revitalizada com a introdução de espécies nativas; as nascentes foram protegidas com a implantação da vegetação sugerida pela legislação ambiental; parte da área foi adequada ao lazer da comunidade e, ainda, a comunidade reconheceu a necessidade das melhorias apresentadas no decorrer do desenvolvimento da pesquisa.

Criou-se, também, uma praça para o lazer da comunidade, o que pode ser considerado um aumento significativo da qualidade de vida da população.

Entre os moradores existe uma preocupação com o acesso à infraestrutura básica do espaço urbano, onde se percebe certo abandono por parte do Poder Público, pois há reclamações quanto à falta de manutenção nas vias públicas e problemas com o esgoto, o qual continua poluindo os recursos hídricos.

Como iniciativa de projetos futuros sugere-se a implantação, no Loteamento Cidade Universitária, de uma estação de tratamento de efluentes e mais estudos que revelem dados mais precisos sobre a qualidade física e microbiológica da água das três nascentes.

Abstract - The green areas of a city are usually governed by the development plans proposed by the municipalities. However, proposals for improvements are usually taken by the community to the relevant bodies, such as City Hall and Public Prosecutor. This work was developed as an aid for possible improvements in the green area of Allotment City University, in Passo Fundo/RS, in order so there is suitable to its original purpose. The stages of development of the methodological work are: bibliographic, mapping the area and existing vegetation; socioeconomic diagnosis of households in housing development, carried out by questionnaire, in which we investigated the perception of the environment by the residents; Proposals for : reforestation of the area with native species, cleaning and protection of springs. The results obtained showed a possible diagnosis socioeconomic community awareness for the recovery of the study area. With these actions, the green area now has a social function for the community, which henceforth is active in the preservation of the site, through the proposals for improvements suggested in this article.

Keywords: Area degraded; Protection of sources; Water.

\section{REFERÊNCIAS}

BRAGA, R. (Org.); CARVALHO, P. F. (Org.). Recursos Hídricos e Planejamento Urbano e Regional. 1. ed. Rio Claro: Laboratório de Planejamento Municipal, 2003 (Boletim Técnico, 131).

CARVALHO, P. F. Repensando as áreas verdes urbanas. Rio Claro: Unesp, Território e Cidadania, 2003.

CHAFFUN, N. Dinâmica global e desafio urbano. In: Bonduki, N. (Org.) Habitat: as práticas bem-sucedidas em habitação, meio ambiente e gestão urbana nas cidades brasileiras. 2. ed. São Paulo: Studio Nobel, 1997.

FANTON, G. Diagnóstico das Condições Ambientais do Espaço Urbano do Município de David Canabarro-RS. Monografia do Curso de Geografia, do Instituto de Ciências Exatas e Geociências, da Universidade de Passo Fundo. Passo Fundo, 2007.

FEIBER, S. D. Áreas verdes urbanas imagem e uso - o caso do passeio público de Curitiba-PR. Revista RA'E GA, Curitiba: Editora UFPR, 2004, n. 8, p. 93-105.

FIORI, S. et al. A Busca Pela Sustentabilidade dos Recursos Hídricos Através do Reuso de Águas. Artigo publicado no I Simpósio de Gestão Integrada de Recursos Hídricos, realizado pela Universidade de Passo Fundo, 2008.

GOOGLEEARTH. Imagem Aérea do Loteamento Cidade Universitária. Disponível em: <http://www.googleearth.com.br>. Acesso em: 18 de abr. 2011.

LEFF, E. A complexidade ambiental. São Paulo: Cortez, 2003.

LIMA, A.M.L.P. et al. Problemas de utilização na Conceituação de termos como espaços livres, áreas verdes e correlatos. In: Congresso Brasileiro sobre Arborização Urbana, II, Anais... São Luiz/MA, 1994. p. 539-550.

LORENSINI, C. et al. Equívocos no planejamento urbano de Santa Maria - RS. 2008. Disponível em: <http:// www.vitruvius.com.br>. Acesso em: 31/3/2011.

MAGOSSI, L. R.; BONACELlA, P. H. Poluição das águas. São Paulo: Moderna, 2003.

MARQUES NETO, R.; VIADANA, A. G. Abordagem biogeográfica sobre a fauna silvestre em áreas antropizadas: o sistema Atibaia-Jaguari em Americana (SP). Revista Sociedade \& Natureza, Uberlândia, v. 18, n.5, p. 5-21, dez. 2006.

MAZZEI, K. et al. Áreas verdes urbanas, espaços livres para o lazer. Revista Sociedade \& Natureza, Uberlândia - MG, 19 (1), p 33-43, jun.. 2007. 
MIANA, Anna Christina. Adensamento e Forma Urbana: Inserção de parâmetros ambientais no processo de projeto. 2010. 394 f. Tese (Doutorado) - Curso de Doutorado em Arquitetura e Urbanismo, Universidade de São Paulo, São Paulo, 2010.

NEFUSSI, N.; LICCO, E. Solo Urbano e Meio Ambiente. 2005. Disponível em: < http://www.nemo.uem.br/>. acesso em: 13/05/2011.

NUCCI, J. C.; Qualidade ambiental e adensamento urbano. São Paulo: Humanitas/FAPESP, 2001. 236p.

OLIVEIRA, C. H.; Planejamento ambiental na cidade de São Carlos (SP) com ênfase nas áreas públicas e áreas verdes: diagnóstico e propostas. Dissertação de Mestrado. Universidade Federal de São Carlos, São Carlos-SP, 1996.

OLIVEIRA, P. T. S. B. DE.; BITAR, O. Y. Indicadores ambientais para o monitoramento de parques urbanos. Interfacehs: Revista de Gestão Integrada em Saúde do Trabalho e Meio Ambiente, v. 4, n. 2, p. 1-14. 2009.

ROTTA, L. A.; NECKEL, A.; GOELLNER, E. Proposta de recuperação e preservação da área verde do Loteamento
Para Onde!?, 7 (1): 10-16, jan./jul. 2013 Divino Girardi no bairro Ipiranga, Ronda Alta/RS. Revista Eletrônica Geoaraguaia. Barra do Garças-MT, v2, n.2, p 1-15, ago./dez. 2012.

SANTIAGO, A. G.; MEDEIROS, R. A. Áreas verdes, praças e comunidade. Episteme, Tubarão, v. 9, n. 26/27, p. 45-48, mar./out. 2002.

SOUZA, M. L. Mudar a cidade: uma introdução crítica ao planejamento e à gestão urbanos. 3. ed. Rio de Janeiro: Bertrand Brasil, 2004.

TEIGA, P. et al,. O Envolvimento da população na reabilitação de um rio urbano (Barcarena - Oeiras). In: Congreso Internacional de Educación Ambiental dos Países Lusófonos e Galiza, 1, 2007, Santiago de Compostela. Anais... España: CEIDA, p. 1-16.

TOLEDO, F. S.; SANTOS, D. G.; Espaços Livres de Construção. Revista da Sociedade Brasileira de Arborização Urbana, Piracicaba - SP, v3, n1, p. 73-91, mar. 2008.

ZANELLA, N.; CECHIN, S. Z. Taxocenose de serpentes no Planalto Médio do Rio Grande do Sul, Brasil. Revista Brasileira de Zoologia, v.23, n.1, p 211-217, 2006. 